\title{
Cultura, desenvolvimento e turismo em Celso Furtado: de uma revisão bibliográfica à aplicação teórica
}

\section{Culture, development and tourism in Celso Furtado: from the literary review to the theoretical application}

\author{
Cíntia Raquel Soares Pinheiro, Luiz Eduardo Simões de Souza
}

\begin{abstract}
RESUMO
O presente estudo constitui-se de uma pesquisa teórica preliminar a partir do ponto de vista do autor Celso Furtado sobre cultura, desenvolvimento e turismo. Empregou-se a metodologia de revisão bibliográfica da obra de Celso Furtado que aborda o tema de Desenvolvimento e Cultura, com vista a aplica-los teoricamente ao turismo. Ainda que o autor não tenha citado a atividade turística em seus ensaios, suas análises servem de subsídio para o estudo do Turismo de Base Comunitária do ponto de vista do desenvolvimento endógeno e da dimensão cultural. A atividade turística, quando executada com políticas públicas corretas e planejadas, propicia a geração de emprego e renda, podendo ser um instrumento propulsor para o desenvolvimento da economia em localidades com potencial turístico, especialmente em Áreas Naturais Protegidas. Reitera-se a necessidade de estudos posteriores que utilizem as obras do Celso Furtado que, como dito, fornece aos pesquisadores um material substancial para estudos e práticas turísticas.
\end{abstract}

PALAVRAS-CHAVE: Desenvolvimento; Cultura; Turismo; Celso Furtado.

\begin{abstract}
This present study is based on a preliminary theoretical research from the point of view of the author Celso Furtado on culture, development and tourism. Its consists in a bibliographical revision of the work of Celso Furtado that explain the theme of Development and Culture, in order to apply them theoretically to tourism. Although the author did not mention the tourist activity in his paper, his analyzes serve as a subsidy for the study of community based tourism from the point of view of endogenous development and the cultural dimension. Tourism, when executed with correct and planned public policies, generates employment and income, and can be a driving force for the development of the economy in places with tourism potential, especially in Protected Areas. The need for further studies using the works of Celso Furtado, which, as said, provides researchers with substantial material for tourism studies and practices is reiterated.
\end{abstract}

KEYWORDS: Development; Culture; Tourism; Celso Furtado. 


\section{Introdução}

Fruto do transbordamento interdisciplinar característico dos grandes cientistas sociais do século $\mathrm{XX}$, pode-se dizer que as configurações históricas e econômicas das relações sociais produtivas foram o grande objeto de estudo de Celso Furtado (1920 - 2004). Porém, o autor não se manteve apenas no plano acadêmico, tendo se dedicado a um intenso envolvimento político.

Ainda que o período da SUDENE nos anos 1950, ou do Ministério do Planejamento de João Goulart (1963), ou mesmo os tempos da formação da CEPAL nos anos 1950 - 1960, e o período como professor da Universidade de Paris X nos anos 1970 atraiam a maior parte dos interessados na vida e obra de Celso Furtado, um período subestimado, mas ainda relevante de sua trajetória se apresenta quando foi Ministro da Cultura no Governo de José Sarney (1985 - 1989).

Ao longo dos seus estudos, Furtado aprimorou o conceito de desenvolvimento, analisando-o sob múltiplas esferas e pioneiramente abordou o enfoque da dominação cultural e suas implicações nas sociedades, como se pode observar desde Desenvolvimento e Subdesenvolvimento, livro de 1962.

O advento da globalização e a visibilidade de malefícios resultantes de explorações predatórias com o único intuito de acumulação de capital, fizeram com que as nações adotassem posturas mais sustentáveis, que não provessem lucros imediatos e esgotamento de recursos, mas que pudessem garantir as gerações presentes e futuras, condições de se desenvolver economicamente.

Para Furtado, o Estado tem um papel importante nessa configuração, onde o planejamento e as estratégias são direcionadas para o bem coletivo da população e não somente à uma minoria que detém o poder.

Seus ensaios não abordam a atividade turística de forma específica, mas através deles, os pesquisadores podem se basear em um profícuo e denso material teórico que serve de base para muitos debates nesse campo ainda pouco explorado.

Contudo, em vários momentos de suas obras específicas sobre 0 desenvolvimento, e também em incursões esparsas sobre o tema da cultura em sentido amplo, o economista mostrou um entendimento do que se espera do pensamento da área, sobretudo em tempos de extrema especialização, como os atuais.

Este estudo não tem a intenção de esgotar o material deixado pelo autor, na realidade, é a base para pesquisas subsequentes que complementem o entendimento das contribuições de Celso Furtado em áreas como o Turismo de Base Comunitária (TBC) e correlatas.

No caso destas notas para discussão, apontamos para a visão multicultural e o reconhecimento do papel das comunidades tradicionais da parte de Celso Furtado como motores para o desenvolvimento, partindo da 
concepção ulterior deste de que o subdesenvolvimento seria um processo cultural.

Sua superação, assim, também se daria na esfera da Cultura. Considerando-se o papel cultural do Turismo, para além do caráter mercadológico do Turismo-Mercadoria, é possível compreendê-lo como um vetor e um meio de interação cultural que permitiria, em última análise, a superação do subdesenvolvimento.

Em uma área multidisciplinar como o turismo, as discussões sobre as questões do desenvolvimento podem ir além do lugar-comum de se apresentar este como atividade promotora ou mesmo relacionada diretamente com certo tipo de concepção desenvolvimentista.

Na verdade, é possível observar-se certa heterogeneidade no debate acerca das concepções de desenvolvimento para o turismo e na própria acepção da atividade-meio turismo para a formulação de conceitos de desenvolvimento

\section{As contribuições de Celso Furtado para a Cultura e o Desenvolvimento}

Para tratar de aspectos sobre a cultura, Celso Furtado buscou aprofundar-se em conceitos de outras ciências, tais como a sociologia e a antropologia, de forma a visualizar a cultura de forma sistêmica. Essas áreas são atreladas a economia, embora ainda pouco explorado por autores da área.

Por seus estudos, Celso Furtado conseguiu elaborar uma gama de textos, livros e artigos que exploram a cultura e a formação cultural brasileira e, para isso, precisou fazer um apanhado da formação histórica do Brasil. Em linhas gerais, o Brasil foi explorado por culturas dominantes europeias, haja vista, tal dominação ainda é visível nos dias de hoje. Como nos diz o autor:

[...] assim, desprezado pelas elites, o povo continua seu processo formativo com considerável autonomia, o que permitirá que as raízes não europeias de sua cultura se consolidem e que sua força criativa se expanda menos inibida, em face da cultura da classe dominante (FURTADO, 1984. Pg. 23).

Dessa forma, expõe-se um primeiro dualismo da formação cultural brasileira. De um lado: a cultura dos povos de origem indígena, de outro, colonizadores europeus que impunham à força sua cultura. Além disso, fica claro o distanciamento entre elite e povo também presente em outros contextos. No contexto acima explicitado, a elite denota civilidade, e o povo, 0 atraso.

Sabe-se também, que o Brasil enquanto colônia nos princípios de sua formação, foi explorado por suas riquezas materiais e o povo aqui presente, escravizado para enriquecer os colonizadores e suas nações. À medida em que os países periféricos, tentam acompanhar o ritmo de acumulação dos países centrais, surge o aumento do abismo entre elite e povo. 
A análise de Furtado sobre o subdesenvolvimento representa um enorme avanço sobre a dicotomia atraso/modernização. Aborda, além disso, o tema da dominação internacional a partir da situação de dependência, recriada permanentemente por meio dos elementos de dependência tecnológica, financeira e cultural que marcam o comportamento das classes dominantes e de suas elites dirigentes (TAVARES, 2000).

Ao longo de suas obras, como característica de seu método de abordagem, Furtado realiza diversos apanhados históricos para explicar 0 abismo que existe entre nações desenvolvidas e subdesenvolvidas e as mazelas decorrentes do acúmulo de produção capitalista nas sociedades periféricas.

O autor em questão, cujas obras constituem-se em bibliografia fundamental para compreensão do Brasil e formulação de políticas públicas, adiciona que:

\begin{abstract}
O desenvolvimento econômico, nas condições adversas, dificilmente se fará sem uma atitude participativa das grandes massas da população. Toda autêntica política de desenvolvimento retira a sua força de um conjunto de juízos de valor que amalgamam os ideais de uma coletividade. E se uma coletividade não dispõe de órgãos políticos capacitados para interpretar suas legítimas aspirações, não está aparelhada para empreender as tarefas do desenvolvimento. Toda medida que se venha a tomar, no sentido de enfraquecer os governos como centros políticos capazes de interpretar as aspirações nacionais e aglutinar as populações em torno de ideais comuns, resultará na limitação das possibilidades de autêntico desenvolvimento na região (FURTADO, 2002, p.41).
\end{abstract}

A fala de Furtado é de tamanha relevância que poderia ser fragmentada e discutida em inúmeras seções do presente diálogo, porém, explanando a intenção posta, o autor defende a participação da população como essencial para o processo de desenvolvimento e do Estado para materializa-las em políticas públicas.

Os membros pertencentes ao território são os agentes capazes de exprimir os seus reais anseios para que sejam materializados pelo Estado ou organismo competente. Modelos prontos de desenvolvimento executados a esmo em localidades com discrepância daqueles originalmente formulados, com via de regra, constituem-se em graves problemas estruturais, políticos e econômicos, tendo como exemplo as políticas neoliberais ${ }^{1}$ em vigência nos países da América Latina e no Brasil, cujas consequências são visualizadas no curto e no longo prazo.

Entender as raízes do subdesenvolvimento em nações que são ricas em recursos naturais e que possuem um cabedal cultural imponente, é uma tarefa que precisa ser analisada para além das políticas macro e microeconômicas, uma vez que, nas palavras de Furtado: " $A$ análise econômica não nos pode dizer por que uma sociedade se desenvolve e a que agentes sociais se deve esse processo" (FURTADO, 1952, p. 321). 
Utilizando-se da palavra atraso, Myint (2010, p.124) adota esse termo para as populações que estão inseridas em territórios que apresentam índices de baixa renda e desigualdade estrutural. Em suas palavras:

O conceito de atraso perderia muito de seu significado se aplicado a grupos humanos homogêneos sem relações econômicas internacionais. A ideia de atraso só se apresenta quando uma economia autossuficiente primitiva ou medieval abre-se a forças econômicas externas e quando sua população entra em contato com outras economicamente mais "adiantadas".

De que forma pode-se aplicar o termo "atrasado" para as populações que viviam no Brasil antes da colonização? De certo que os colonizadores que aqui chegaram utilizaram de força física e pressão psicológica para desterritorializar ${ }^{2}$ os nativos, transformando-os em escravos ou utilizando de seu conhecimento do território para benefício próprio e enriquecimento da metrópole.

Sergio Buarque de Holanda utilizou a célebre frase "somos ainda hoje uns desterrados em nossa própria Terra” (HOLANDA, 1995, p.27). Se décadas após a independência o teórico utilizou tal frase ao retratar o povo brasileiro, o que dizer dos índios e dos outros povos e comunidades tradicionais? O paradoxo analisado por Mynt diz ainda que "essas pessoas são consideradas atores (ainda que fracassados) na luta econômica" (MYINT, 2010, p. 125).

À medida em que os países periféricos, tentam acompanhar o ritmo de acumulação dos países centrais, surge o aumento do abismo entre elite e povo. A história brasileira é marcada por exemplos em que as classes dominantes defendiam ferrenhamente seus privilégios (TAVARES, 2000).

Ao mesmo tempo em que economias do centro desejam manter economias da periferia em estado de exploração, essa mesma dinâmica está presente no próprio território, na função da elite, da burguesia, dos trabalhadores locais e entre os múltiplos atores pertencentes ao território. Detalhadamente:

O imperialismo extrai praticamente todo o excedente dos países subdesenvolvidos. É o obstáculo fundamental a qualquer processo real de desenvolvimento. A burguesia local, por sua vez, está integralmente subordinada ao imperialismo. Como este explora os trabalhadores locais através do comércio internacional e das empresas multinacionais, não resta outra alternativa à burguesia local para poder se apropriar também ela do excedente senão superexplorá-los (FURTADO 1985, p. 31).

Para além de um processo mecânico ou fortuito - extremos encontrados em padrões de análise limitados sobre o desenvolvimento Furtado chama a atenção para a complexidade das relações sociais, 
econômicas e culturais e nos apresenta o conceito do "sistema de cultura".

\begin{abstract}
Observado enquanto processo dinâmico com aspectos materiais e imateriais que incidem diretamente em mudanças nos indivíduos e na coletividade. Este modelo, que nos dá uma visão integrada da cultura como sistema, está formulado a um nível de abstração tão alto como a hipótese de Marx. Temos a cultura dividida em dois grandes segmentos e o desenvolvimento mais rápido da base material exigindo adequadas acomodações na superestrutura não material. [...] $O$ que existe de fundamental e comum aos dois modelos é a constatação de que, sendo a cultura um conjunto de elementos interdependentes, toda vez que em determinadas condições históricas avança a tecnologia e se desenvolvem as bases materiais, todos os demais elementos serão chamados a ajustar-se às novas condições, ajustamentos esses que darão origem a uma série de novos processos, com repercussões inclusive sobre a base material. [...] O que interessa aqui assinalar é o reconhecimento de que o processo de rápida mudança que caracteriza a nossa cultura reflete as transformações intensivas que uma tecnologia em acelerado desenvolvimento introduz no seu processo produtivo. E enquanto estivermos neste terreno, permaneceremos dentro do marco da hipótese simplificada que formulou Marx partindo da concepção dialética da história (FURTADO, 1964: 18-19).
\end{abstract}

O autor acredita que mudanças culturais decorrentes da inserção de uma nova tecnologia nos processos produtivos culminam em maior dinamismo, geram reações em cadeia e aumentam o produto social e o excedente.

O contrário também é visto, onde mudanças na cultura não-material influem sobre a cultura material. Esta hipótese é encontrada em seus ensaios sobre a dimensão cultural do subdesenvolvimento.

Não é fortuita, assim, a síntese que transparece em uma conferência de 1984 sobre cultura, nela, Furtado entende o papel transformador da cultura sobre o subdesenvolvimento (e também seu outro sentido, o de perpetuador de suas condições), e reconhece que a natureza de tal papel é dada pelo "agir pensado" do pensamento para a ação (FURTADO, 2012, p. 30).

Isso explica e caracteriza muito da ação política de Celso Furtado em sua relação com sua obra intelectual. Nessa mesma conferência, Furtado apresenta seis teses sobre a cultura brasileira e sua relação com 0 subdesenvolvimento. Nelas, resumidamente, Furtado reconhece a herança histórica para com os processos dados pela expansão marítima europeia e o renascimento. 
Também reconhece o papel das culturas africana e indígena, sugerindo um interessante pensamento alternativo à tese da submissão cultural dessas últimas à europeia, o que caracterizaria nossa visão exogeinista do reconhecimento cultural: os portugueses, graças à tecnologia superior, teriam maior capacidade de alimentação em suas fontes culturais europeias (FURTADO, 2012, p. 36) do que as demais.

Ao analisar as obras de Furtado, César Bolaño concluiu: " $A$ homogeneização dos padrões de consumo no centro, contrapõe-se a uma crescente discrepância de padrões de vida entre uma minoria privilegiada e a massa da população nos países periféricos" (BOLAÑO, 2015. P. 147) .

Em países de economia dependente como o Brasil, uma política de desenvolvimento nociva implica em um elevado desgaste de muitos dos seus valores culturais visto que as rupturas com o passado em favor de uma "modernidade" não são necessariamente criativas, mas sim, refletem imposições da lógica do processo de acumulação e competitividade (FURTADO, 2012, p. 123). O autor já havia afirmado: "O problema da dominação cultural, antigo como a história dos contatos entre civilizações, assume novas formas em que prevalece o poder financeiro " (FURTADO, 2013, p. 12).

O ponto de partida para uma mudança de estratégia, foi a tomada de consciência de que a qualidade de vida de um povo nem sempre melhora com o avanço da riqueza ${ }^{3}$, uma vez que os modelos de desenvolvimento dos anos 50 tendiam para a "reprodução da estratificação social herdada do passado" (FURTADO, 2012, p. 109).

$\mathrm{Na}$ contemporaneidade, intelectuais utilizam-se da cultura de forma transdisciplinar: economistas, sociológicos, antropólogos, geógrafos, turismólogos, profissionais da saúde como psicólogos, médicos, farmacêuticos, ou seja, uma gama de profissionais estão analisando essas questões que cobram urgência dos gestores públicos e da sociedade civil em alargar o debate para que sejam implantadas políticas culturais que, comprovadamente $^{4}$, auxiliam no desenvolvimento socioeconômico de nações, territórios, povos e comunidades.

Para Furtado:

Não se pode desconhecer que, em um país subdesenvolvido, os aspectos econômicos do desenvolvimento social assumem grande emergência. Não é possível educar os homens sem antes lhe matar a fome. Contudo, relegar a segundo plano outros aspectos do problema social seria comprometer o desenvolvimento subsequente da cultura que deverá moldar o homem do futuro (FURTADO, 1962, p. 91, grifo nosso).

Como homem de ação que era, não soariam menos do que coerentes as palavras do discurso de posse como Ministro da Cultura, em 1986: " $A$ política cultural, em face da revolução das tecnologias de comunicação, terá de preocupar-se não apenas em democratizar o acesso aos bens culturais, mas também em defender a criatividade" (2012, p. 54). 


\section{A cultura em comunidades tradicionais}

Ao se implantar políticas culturais, é necessário que os dirigentes governamentais tenham uma aguda percepção do momento histórico, além do imprescindível: a vontade coletiva (FURTADO, 2012).

Por extensão, o desenvolvimento através da dimensão cultural depende da disposição de um povo, com sua visão de mundo, crenças, valores, moral, com concepções éticas, estéticas e ontológicas. Esses fatores produzem efeitos inegáveis nos comportamentos, nas escolhas, nas decisões e ações dos indivíduos em sociedade (BIRKNER; BAZANELLA, 2013).

Sociedades como a brasileira e a latino-americana que são economicamente dependentes, necessitam de uma política cultural consistente, que abarque a pluralidade e a multiculturalidade de seus territórios.

Quando Furtado se refere a cultura como uma das bases do desenvolvimento, ele amplia a nossa noção de políticas culturais, pois além de agregar uma multiplicidade de agentes sociais, uma política orientada para o desenvolvimento cultural só pode ser implementada com 0 protagonismo das populações e que uma "política de desenvolvimento deve ser posta a serviço do processo de enriquecimento cultural" (FURTADO, 1984, p.32).

O conceito de Política Cultural Nacional não pode permitir que haja homogeneização ou a escolha de uma "cultura predominante"5, ao contrário, faz-se necessário abranger o conceito de identidade cultural dos diversos povos, a fim de manter com o passado uma relação capaz de enriquecer o presente (FURTADO, 2014).

Esse processo nada mais é que um desenvolvimento endógeno, cujo cerne incide na consolidação e manutenção das identidades culturais ao passo em que se explora as potencialidades criativas dos indivíduos afim de mitigar uma possível dependência cultural e imitação de padrões de consumo próprios do capitalismo ${ }^{6}$.

Essa concepção perpassa a complexidade que a atividade turística está envolvida, alternando as questões econômicas, encontradas no turismo de massa, passando a considerar inclusive, questões sociais, culturais e ambientais, que envolvem as comunidades receptoras.

Ou seja, a ideia de desenvolvimento está no centro da visão de mundo que prevalece na época atual. A partir dela, o homem é visto como um fator de transformação, tanto no contexto social e ecológico que está inserido como de si mesmo (FURTADO, 1984).

Dessa forma, o desenvolvimento, ainda que seja um processo de transformação, não pode ser aplicado em caráter de acumulação de capital em territórios protegidos onde habitam comunidades tradicionais. Não cabe em tais localidades, utilizar a atividade como forma de apropriação de 
excedentes para acumulação e enriquecimento da metrópole à maneira dos tempos do Brasil Colônia.

Comunidades tradicionais são sensíveis em suas múltiplas características, mas se possuírem vocação turística, a atividade pode, e deve ser explorada em favor da melhoria da qualidade de vida da população, da manutenção de sua cultura e com mínimos impactos sobre o meio ambiente.

Furtado nos explica o processo de dominação capitalista:

(...) A ideia de desenvolvimento apenas tem sido de utilidade para mobilizar os povos da periferia e leva-los a aceitar enormes sacrifícios, para legitimar a destruição de formas culturais 'arcaicas', para 'explicar' e fazer 'compreender a necessidade' de destruir o meio físico, para justificar formas de dependência que reforçam o caráter predatório do sistema produtivo (FURTADO, 1974, p. 75).

Segundo Coriolano (2006, p. 373) o que ocorre é que "o turismo não é diferente de nenhuma atividade capitalista, não é maldição e nem benção, é resultado das práticas políticas dos discursos hegemônicos e dos de resistência". Para alguns autores, não há possibilidade de mudanças dentro do capitalismo, para outros, as resistências e lutas são tentativas de desconstrução desse sistema.

No sentido oposto, em projetos de TBC, a cultura local emerge como ponto de fascinação, os locais massificados e homogêneos, ou ainda, grandes empreendimentos erguidos puramente para fruição e lazer, não são mais cobiçados pelos turistas.

Emerge, então, a busca por locais de rara beleza natural com populações que sobrevivem essencialmente deste meio, sem grandes integrações com o global, na busca por experiências mais autênticas. Doravante, problemas aparecem ao atrelar a cultura à atividade turística, com fins puramente mercantis:

\begin{abstract}
A busca dos elementos característicos e diferenciais de cada cultura aparece como uma necessidade de mercado, a cultura autóctone é a matéria-prima para a criação de um produto turístico comercializável e competitivo internacionalmente. O legado cultural, assim transformado em produto para o consumo, perde seu significado. A cultura deixa de ser importante por si mesma e passa a ser importante por suas implicações econômicas. A história não é importante porque mostra as raízes, mas porque traz dinheiro (BARRETO, 2007, p. 106):
\end{abstract}

Um dos grandes desafios do turismo é desenvolver a qualidade de vida dos moradores do sítio ${ }^{7}$ e vivências reais para os turistas, em um espaço que articule passado e presente, tradição e modernidade. 
Mas não podemos nos ater somente a essa dicotomia, o debate é mais profundo, por isso, há uma necessidade de aplicar novas bases para um turismo presente nas agendas de pesquisa e dos governos, que seja integrada em uma política de desenvolvimento nacional que considere a pluralidade cultural de seu extenso território.

Podemos afirmar, então, que as políticas culturais não devem ter apenas objetivos mercantilistas, mas sim, liberar e estimular o potencial criativo das comunidades. Portanto, a atividade turística deve ser realizada com base em princípios éticos e colaborar primeiramente - com a comunidade receptora cumprindo os preceitos da Carta Magna e do Plano Nacional de Turismo.

\section{Desenvolvimento, Turismo e Cultura em Áreas de Proteção Ambiental}

Para que haja uma real promoção do desenvolvimento de comunidades tradicionais, a gestão pública deve dar suporte ao combate à pobreza de forma sustentável, garantindo a cada cidadão o acesso aos bens e serviços públicos que permitem o desenvolvimento humano, dito, inclusive na Constituição de 1988 no Art. 215 "o Estado garantirá a todos o pleno exercício dos direitos culturais". Ou seja, a Cultura é um direito constitucional de todos os cidadãos e com isso, legitima-se as intervenções do Estado no campo cultural, o que dá base para políticas públicas elaboradas e aplicadas em nosso país.

O desenvolvimento que se busca através da atividade turística de base comunitária é, antes de mais nada, um desenvolvimento em escala humana, que atenda as demandas sociais. Nele, o homem passa a ser a medida de todas as coisas e não apenas os índices quantitativos e o lucro.

Para Sansolo e Bursztyn (2009, p. 152) existe "[...] um potencial vínculo entre as questões relativas à atividade turística e à conservação ambiental', dado que $80 \%$ das experiências de TBC mapeadas no Brasil se deram nas proximidades ou no interior de áreas protegidas, além de estarem com frequência assentadas em Áreas de Preservação Permanentes, como manguezais, margens de rios e restingas.

As preocupações sobre o meio ambiente e esgotamento dos recursos naturais ensejam a necessidade de salvaguarda-los para a manutenção das necessidades da população atual bem como para as gerações futuras. Áreas Naturais de todo o globo precisam ser protegidas e o Brasil, apesar de deter a maior biodiversidade do mundo, só inicia efetivamente esse processo a partir dos anos 1990.

Após uma década de tramitação, a da lei do Sistema Nacional de Unidades de Conservação (SNUC), foi aprovada no dia 21 de junho de 2000 , e sancionada pelo presidente no mesmo ano. O debate aberto com a sociedade permitiu que socioambientalistas e suas ideias fossem incorporadas na lei (SANTILLI, 2005). 
Sendo assim, as UCs podem ser definidas como áreas territoriais que tem por finalidade a sua conservação. Possuem regras de manejo e de uso, objetivando a salvaguarda das espécies animais e vegetais, as belezas cênicas, o modo de vida e a cultura dos Povos e Comunidades que tradicionalmente ocupam as terras, dependendo da categoria de manejo.

De acordo com o SNUC, os povos e comunidades tradicionais historicamente negligenciados pelo poder público - transformam-se em sujeitos de direito, com o apoio da academia, de instituições multilaterais e do governo, amparados por dispositivos legais balizados pela Carta Magna. São ainda, cogestões dos territórios de uso sustentável e podem, com isso, caminhar para o desenvolvimento que almejam.

Para Sahlins (1997), comunidades constituem-se em exemplos de populações que se distinguem entre si pelos modos específicos de viver e se apropriam de elementos externos, regidos por lógicas e sistemas vistos como impositivos, e os transformam em favor de seus próprios referenciais culturais locais.

As atividades e a gestão do território são compartilhadas visto que áreas protegidas, são espaços distintos de ordenamento territorial, mas não são um entrave para um desenvolvimento sustentável repousado em seu tripé.

Dessa forma, há uma ruptura com um modo de vida essencialmente extrativista, fato que confere uma nova dinâmica econômica, social e cultural no lugar.

\section{Considerações finais}

Diante de cenários com extremas desigualdades ainda que privilegiados por um cabedal cultural imponente, de que forma seria possível à população marginalizada valer-se do arcabouço da cultura para impulsionar o desenvolvimento? Imediatamente ao nos depararmos com esse questionamento, arremetemos de pronto para contextualizar o Brasil, com seu extenso território, suas particularidades regionais e seus aspectos pluriculturais.

As contribuições de Celso Furtado para o desenvolvimento sob a perspectiva cultural, tem amplas possibilidades de aplicação à atividade turística de base local. Em áreas de proteção ambiental, a execução da atividade turística culmina no fortalecimento de organizações locais, fornece ferramentas para implementação do gerenciamento cooperativado e distribuição do poder público sobre os recursos do turismo, acresce valor aos produtos extraídos e atrativos turísticos (naturais, culturais, econômicos e sociais).

Apesar disso, ainda são incipientes as metodologias que sejam capazes de promover 0 desenvolvimento de localidades em áreas protegidas utilizando o turismo de base comunitária e a valorização do patrimônio cultural imaterial e material, que nas análises de Furtado também são mola propulsora do desenvolvimento. 
A comunidade precisa ser protagonista desse processo de desenvolvimento e fomentar o chamado desenvolvimento endógeno de forma a maximizar o seu papel criativo. "A endogeneidade outra coisa não é senão a faculdade que possui uma comunidade humana de ordenar o processo acumulativo em função de prioridades por ela mesma definidas" (FURTADO, 1984, p. 108).

Em contrapartida, esse tipo de intervenção por parte das forças endógenas não deve ser executado a esmo, é necessário qualificação, planejamento e estratégias bem articuladas para que se possa lograr êxito. Para tanto, "[...] a geração de conhecimentos sobre a realidade local, e a promoção de uma atitude proativa para o desenvolvimento, fazem parte evidente de uma educação que pode se tornar em instrumento científico e pedagógico da transformação local' (DOWBOR, 2006, p. 14).

Reitera-se a necessidade de estudos e de políticas públicas sistemáticas para que comunidades que ainda não estão submetidas a lógica do sistema capitalista, possam ter sua cultura reconhecida e valorizada.

Pesquisas acadêmicas e a aproximação da universidade na avaliação, estruturação e implementação de iniciativas de desenvolvimento em áreas protegidas, possibilitam o enriquecimento e alargamento das fronteiras do conhecimento por parte dos atores envolvidos. Somente a partir da análise/avaliação das iniciativas em curso pode-se compreender o que, de fato, demonstra ser factível e exequível.

\section{Referências Bibliográficas}

BOLAÑO, C. Cultura e desenvolvimento: reflexões à luz de Furtado. EDUFBA. 2015.

BRASIL. Ministério do Meio Ambiente. SNUC - Sistema Nacional de Unidades de Conservação da Natureza: 2000.

CANEPA, C. Cidades Sustentáveis: o município como lócus da sustentabilidade. São Paulo: Editora RCS, 2007.

CORIOLANO, L.N.M.T. Turismo: prática social de apropriação e de dominação de territórios. In: LEMOS, A.G. (Org). América Latina: cidade, campo e turismo, 2006, p. 367-378.

DOWBOR, L. A intervenção dos lugares centrais e o turismo ambiental na obra de Christaller. In: LEMOS, A.I.G. (Org.). Turismo: impactos socioambientais. 3. ed. São Paulo: Polis, 2006.

FURTADO, C. A pré-revolução brasileira. Rio de Janeiro: Fundo de Cultura, 1962. 119 p. (Coleção Perspectivas do Nosso Tempo).

FURTADO, C. Dialética do Desenvolvimento. Rio de Janeiro: Fundo de Cultura, 1964. 
FURTADO, C. Criatividade e Dependência na civilização industrial. São Paulo: Círculo do Livro, 1978.

FURTADO, C. Pequena introdução ao desenvolvimento: enfoque interdisciplinar. São Paulo: Companhia Editora Nacional, 1980.

FURTADO, C. Teoria e Política do Desenvolvimento Econômico. São Paulo: Abril Cultural, 1983.

FURTADO, C. Cultura e desenvolvimento em época de crise. São Paulo: Paz e Terra, 1984.

FURTADO, C. O longo amanhecer: reflexões sobre a formação do Brasil. São Paulo: Paz e Terra, 1999.

FURTADO, C. Em busca de um novo modelo: reflexões sobre a crise contemporânea. São Paulo: Paz e Terra, 2002.

FURTADO, C. 0 mito do desenvolvimento econômico. Rio de Janeiro: Paz e Terra, 1975. Globalização em Tempos de Regionalização Repercussões no Território Santa Cruz do Sul, RS, Brasil, 9 a 11 de setembro de 2015

FURTADO, R.F.D'A. (org.) Celso Furtado e a dimensão cultural do desenvolvimento. Rio de Janeiro: Centro Internacional Celso Furtado, 2013.

FURTADO, R.F.A. (org.). Ensaios sobre cultura e o Ministério da Cultura. Rio de Janeiro: Contraponto; Centro Internacional Celso Furtado, 2012.

SANSOLO, D.G; BURSZTYN, I. Turismo de base comunitária: potencialidade no espaço rural brasileiro. In: BARTOLO, R; SANSOLO D.G; BURSZTYN, I (Orgs.). Turismo de base comunitária: diversidade de olhares e experiências brasileiras. Rio de Janeiro: Letra e Imagem, 2009.

SANTILLI, J. Socioambientalismo e novos direitos. São Paulo: Ed. Peirópolis, 2005.

TAVARES, M.C. (Org.). Celso Furtado e o Brasil. São Paulo: Editora Fundação Perseu Abramop. 173, 2000.

\section{Notas:}

1 As experiências neoliberais compartilham traços importantes. Alguns são relativamente
abstratos e universais, como o poder crescente das finanças e as limitações cumulativas da
democracia política, enquanto outros são relativamente concretos e específicos a cada país,
como as privatizações e a disseminação de organizações não-governamentais em áreas
que, anteriormente, pertenciam ao domínio do Estado. Embora essas características
comuns impliquem que o neoliberalismo não possa ser adequadamente descrito na esfera
meramente conjuntural, elas não são suficientemente gerais ou historicamente distintivas
para definir um novo modo de produção. Inevitavelmente, portanto, análises do
neoliberalismo perpassam distintos níveis de abstração dentro do capitalismo, incluindo
algum tipo de compreensão dos conceitos básicos da teoria marxista como a mercadoria, o
valor e a força de trabalho, até a descrição da conjuntura, passando por entendimentos
específicos da exploração, das classes, da concorrência, da formação dos preços, do
Estado e do gerenciamento da acumulação, e do comércio internacional. (FILHO, 2015,
p.59). Harvey (2005, p. 27) nos apresenta duas interpretações para o neoliberalismo. Na
primeira, ele é visto como "um projeto utópico de realizar um plano teórico de reorganização
do capitalismo" e na segunda, é interpretado como "um projeto político de restabelecimento
das condições de acumulação do capital e de restauração do poder das elites econômicas". 
2 Conceito cunhado na filosofia e adaptado para a Geografia e que em essência pura significa: "Saída de um território para reterritorializar em outra parte". Ver: Haesbaert e Bruce (2009).

${ }^{3}$ Furtado acredita que a acumulação de recursos induz ao aumento do desperdício e não a uma diversificação dos hábitos de consumo, nem a um enriquecimento da vida. (FURTADO, 2012, p. 109)

4 Em Democracia na América (2005), Alexis de Tocqueville analisou as particularidades culturais do povo americano que foram fundamentais para transformar os EUA na potência que se consolidou. Outro autor importante foi Putnam (1996) cujo trabalho constituiu-se obra de referência nos estudos sobre a intersecção da cultura, política e econômica que explicam porque algumas sociedades são mais desenvolvidas que outras.

5 Dos 5,4 mil projetos contemplados pela Lei 8.313/91 conhecida como Lei Rouanet no ano de 2015, 66,1\% eram da Região Sudeste e 20\% provenientes da região Sul. Na Sequência, a região Nordeste tem $9,1 \%$ do universo dos projetos aprovados no Brasil, seguida pela região Centro-Oeste com 3,6\% e Norte com 0,9\%. (MINC, 2016). Diante dos números fica evidente a necessidade de revisão da lei e dos dispostos que perpetuam a desigualdade entre as regiões.

6 Com uma mistura de otimismo e descrença, Celso Furtado militou em favor da dimensão cultural do desenvolvimento, para ele, a minoria pertencente a elite brasileira parecia composta por indivíduos "obsessos pela mais estreita lógica economicista ditada pelos interesses de grupos privilegiados e empresas transnacionais. "O que acontecia e ainda acontece é uma uniformização dos padrões de comportamentos, que nada mais é do que a base da criação de grandes mercados. O que o autor mais temia era que fossemos "reduzidos ao papel de passivos consumidores de bens culturais concebidos por outros povos." (FURTADO, 2012, p.35)

7 Sítio aqui entendido como lugar de relações vinculantes, entidades imateriais que relacionam indivíduos e organizações sociais, um espaço que agrega comportamentos individuais e coletivos e suas manifestações, dada uma região. Ver Heidegger (1976) e Zaoual (2006).

Cíntia Raquel Soares Pinheiro: Universidade Federal do Maranhão, São Luis, MA, Brasil.

E-Mail: cintiapinheiro03@gmail.com

Link para o currículo Lattes: http://lattes.cnpq.br/4185274068756430

Luiz Eduardo Simões de Souza: Universidade Federal do Maranhão, São Luis, MA, Brasil.

E-Mail: luizedusouza@gmail.com

Link para o currículo Lattes: http://lattes.cnpq.br/6294050144240748

Data de submissão: 06 de junho de 2016

Data de recebimento de correções: 27 de novembro de 2016

Data do aceite: 27 de novembro de 2016

Avaliado anonimamente 